\title{
El papel de la psicología ante los retos del pos-conflicto
}

Entrevista a María Patricia Vaca Vaca

Profesora e Investigadora Departamento de Psicología

Facultad de Psicología Universidad de La Sabana

Juan Sebastián

Castillo

Estudiante de Ciencia Políticay

Sociología

juansebastiancastillocastro@gmail.com

Por:

Mónica Alexandra Ramírez G.

Estudiante de Psicología y Sociología

monica10ramirez@gmail.com

Entrevista recibida el 12/03/2018 y aprobado el 13/03/2018

Cómo citar este artículo:

Castillo Castro, J., \& Ramírez Guevara, M.(2018). El papel de la psicología ante los retos del conflicto. Trans-Pasando Fronteras, (11).

${ }^{1}$ Magister en Psicología Social Comunitaria, Universidad Javeriana. Investigadora Grupo Contexto y Crisis, Línea: Inclusión y Redes Sociales. 
Juan Sebastián Castillo (JSC): ¿Cuál cree usted que es el papel de la psicología en la construcción de paz? y ¿cómo ha cambiado este papel, en el panorama actual?

María Patricia Vaca (MPV): La Psicología como ciencia social debe contribuir a la construcción de una cultura de paz, posibilitando y /o favoreciendo nuevas formas de interacción desde los diferentes ámbitos del ejercicio de la profesión; interacciones fundamentadas en el respeto a la diferencia, la tolerancia, y la gestión pacífica del conflicto. En este sentido debe orientar su praxis a lograr una transformación cultural que promueva esas formas de relación.

Reconociendo la importancia de abordar los problemas desde una perspectiva Psicosocial que trascienda los marcos de análisis individual para acercarse a comprender la complejidad e implicaciones del conflicto que hemos vivido.

JSC: ¿Considera que en el gremio hay la suficiente cualificación para la atención de víctimas en el proceso de reparación integral y todo lo relacionado con los retos/limitaciones que implica dar esta atención?

MPV: Considero que al interior del gremio se reconoce la necesidad de cualificar cada vez más a los psicólogos, para dar respuesta a las necesidades de las víctimas. Este interés es evidente desde las acciones que realiza el colegio Colombiano de Psicólogos, que como agremiación nos representa. También desde los procesos de formación de los estudiantes, en las diferentes universidades, se evidencia la responsabilidad que ha asumido la academia frente a ésta realidad del país. 
Mónica Ramírez (MR): ¿Es posible que la forma en la que se intervino psicológicamente a las víctimas en el pasado haya tenido consecuencias negativas para estas?

MPV: Es posible que por falta de cualificación se hayan cometido errores anteriormente, entre ellos la Revictimización, pero en este momento se cuenta con el recurso humano para dar respuesta de manera idónea a las necesidades de las victimas

JSC: ¿Cree usted que en la actualidad las víctimas del conflicto ven a la psicología como una ciencia legítima de la cual pueden recibir ayuda?

MPV: Considero que cada vez más se reconoce y se hace más visible el valor del acompañamiento psicológico, esto es especialmente importante si se tiene en cuenta que este es un país en donde la salud mental es "invisible" y en donde en muchos contextos la ayuda psicológica es estigmatizada.

MR: Por otro lado, ¿siente que la disciplina se encuentra preparada para afrontar el proceso de reinserción de ex-combatientes?

MPV: Existen experiencias significativas que demuestran el interés de los psicólogos por dar respuesta a las necesidades de estos procesos; algunas de estas experiencias han sido sistematizadas y se convierten en referentes del conocimiento a aplicar en ámbitos particulares de reinserción.

JSC: ¿Cuál cree usted que han sido/y serán los principales retos? 
MPV: El reto fundamental está en lograr incluir a los excombatientes en las diferentes dinámicas de nuestra sociedad, (laboral, política, educativa), lograr resignificar el miedo y la desconfianza que permea la mirada estigmatizada que la sociedad tiene frente a ellos.

MR: ¿Cree usted que uno de los retos a enfrentar en un escenario de posconflicto es la desnaturalización de la violencia como un fenómeno cotidiano?

MPV: La construcción de la Paz pasa por la desnaturalización de la violencia, por el reconocimiento de su complejidad y de las profundas implicaciones que tiene en la vida de las personas. El desnaturalizarla permite comprenderla como una realidad que se puede trasformar.

JSC: Respecto a los psicólogos que ejercen en el campo organizacional, ¿Cómo puede adaptar su trabajo y su metodología para los procesos de contratación e identificación de talentos en empresas que decidan acogerse a dar oportunidades laborales a ex-combatientes?

MPV: Tendrán que repensar las formas como tradicionalmente han participado en los procesos de selección y contratación. Pienso que las herramientas con las que han trabajado no se ajustan a las condiciones particulares, e historia de los excombatientes. Es un reto tanto para las organizaciones como para los Psicólogos que ejercen en éste campo. Deben generarse nuevos parámetros para la inclusión de los excombatientes en el mundo laboral, parámetros que demandan por parte del psicólogo una postura ética y política que permita reconocer diferentes saberes y prácticas 
MR: ¿Es ésta una manera para crear espacios de inclusión social, o desde que otros ámbitos de la disciplina se pueden construir?

MPV: Desde todos los ámbitos de la Psicología se puede y se debe trabajar para generar espacios de inclusión. Es parte de la responsabilidad ética del ejercicio de la Psicología. El campo organizacional es solamente uno de los ámbitos del ejercicio de la Psicología

JSC: En el campo de la educación, ¿Cuál puede ser el aporte desde los procesos pedagógicos y el acompañamiento psicológico a los menores de edad desmovilizados que empiezan a hacer parte de instituciones educativas?

MPV: Las Instituciones Educativas se constituyen en un contexto fundamental de socialización, son espacios de reproducción cultural en el que se pueden perpetuar formas de relación excluyente, o por el contario resignificarlas. Desde ese planteamiento se convierte en un contexto privilegiado para pensar formas de relación diferentes, desde la práctica docente, respaldada por un trabajo interdisciplinario con psicólogos, trabajadores sociales y antropólogos principalmente.

MR: De qué manera cree que las otras disciplinas -tales como sociología, antropología, derecho y ciencia política- se enfrentan a los retos que se han mencionado anteriormente, $y$ a su vez ¿Cómo otras ciencias sociales pueden contribuir en este escenario del post acuerdo?

MPV: Ante todo, las disciplinas de las ciencias sociales deben asumir un compromiso político y ético con la trasformación cul- 
tural que demanda un escenario de posconflicto. El trabajar desde una perspectiva interdisciplinar, a partir de propuestas comunitarias y de manera articulada con las políticas públicas permitirá tener mayor efectividad en los procesos de reinserción, ya que se requiere un acompañamiento integral, no sólo a los reinsertados sino a las comunidades a las cuales se reintegrarán. 